\title{
Influence of flight shape on discharging profiles of granular material in rotary dryer
}

\author{
Ilham Benhsine ${ }^{1, \star}$, Mustapha Hellou ${ }^{1, \star \star}$, Franck Lominé ${ }^{1, \star \star \star}$, and Yves Roques ${ }^{2, \star \star \star \star}$ \\ ${ }^{1}$ INSA, LGCGM, EA3913, F-35708, Rennes, France \\ ${ }^{2}$ All / CERA, BP10180, F-35803, Dinard, France
}

\begin{abstract}
In this work, Discrete Element Method (DEM) is used in order to calculate the motion of granular material in rotating dryers. We are particularly interested in analysing the effect of flight shape on the behaviour of spherical particles in the cross section of the dryer. We will be using two segments flights and three different profiles : a straight flight $\left(180^{\circ}\right.$ between both segments), an angled flight (with an angle of $\left.120^{\circ}\right)$ and a rightangled flight $\left(90^{\circ}\right)$. The results show that the profile of the flight affects significantly the motion of the particles in the cross section of the dryer. Changing the angle between the segment's flight, changes the flight loading and thus the material hold-up which leads to different discharging profiles of the flight. For a right angled flight, the range of the discharge angle increases leading to a more uniformized cascade pattern in time and an enlarging of the area occupied by the curtains of particles. The specific durations (discharging time, falling time) are also determined and studied as a function of the flight shape.
\end{abstract}

\section{Introduction}

Drying granular materials can be defined as the removal of moisture from a solid product. The moisture commonly consists of water. Materials are dried to ease handling, to preserve materials for storage and shipment and mostly they must be dried to bring their moisture content to a specific value before being sold [1].

Rotating dryers are widly used in industry to dry variety of solids [1]. They consist of long drum driven at low speed. The rotation speed, $\omega$, is selected according to the desired mode of bed motion which is characterized by the Froude number $\omega^{2} R / g$ [2], where $R$ is the inside radius of the drum and $g$ is the acceleration due to gravity. Industrial rotary dryer is a tube of length $L$ of circular cross section of a diameter $D$, with aspect ratio $L / D$ about 10 . The drum can be horizontal or slightly inclined [3], [4], [5].

Wet granular material is introduced into the upper inlet of the drum. Then the material accumulates and progress through the drum due to the combined action of the rotation of the drum, the slope of the drum -if present- and the hot gas flow passing through the drum. The dried product leaves the drum from its other extremity.

The dryers are usually fit with flights, which consist of slab made of steel distributed on the periphery of the cross section and periodically along the tube. Flights carry the solid particles and disperse them into the hot gas flow. Flights used in industrial dryers can have complex shape.

\footnotetext{
${ }^{\star}$ e-mail: ilham.benhsine@insa-rennes.fr

$\star \star$ e-mail: mustapha.hellou@insa-rennes.fr

$\star \star \star$ e-mail: franck.lomine@insa-rennes.fr

$\star \star \star \star$ e-mail: yves.roques@ roullier.com
}

However, for theoretical and experimental purposes, simple flight shapes are frequently considered composed by one , two or three segments ([6], [7], [8], [5], [9]).

Several topics that interest scientists and engineers in connection with heat and mass transfer arise in the problem of rotary dryers. The most important of them are the behaviour of the material bed, the holdup of the material by the flights, the material curtains and the mean residence time. While the behaviour of the granular bed material is greatly studied by the DEM approach [10], [11], the other topics are treated essentially with theory or experiments. Thus, most of the studies on the subject of the holdup of the material use the approach of bulk material [12], [6], [8], [5], [9]. Experiments also showed that the mean residence time is affected by the flight's shape. A drum fitted with right-angled flights has a higher residence time than a drum fitted with straight flights [13].

In order to study the effect of flight shape on the behaviour of the granular material, we use EDEM, a highperformance software for bulk material flow simulation based on the Discrete Element Method. This study is conducted to investigate the influence of the flight shape on the holdup. And it is also extended to the analysis of the falling length and falling time of particles in the cross section of the dryer. The flight profiles chosen are: straight flight, large angled flight and right angled flight.

\section{Description of the problem and simulation parameters}

We are interested to study the granular motion in a transverse cross section of the drum. Due to the periodicity 


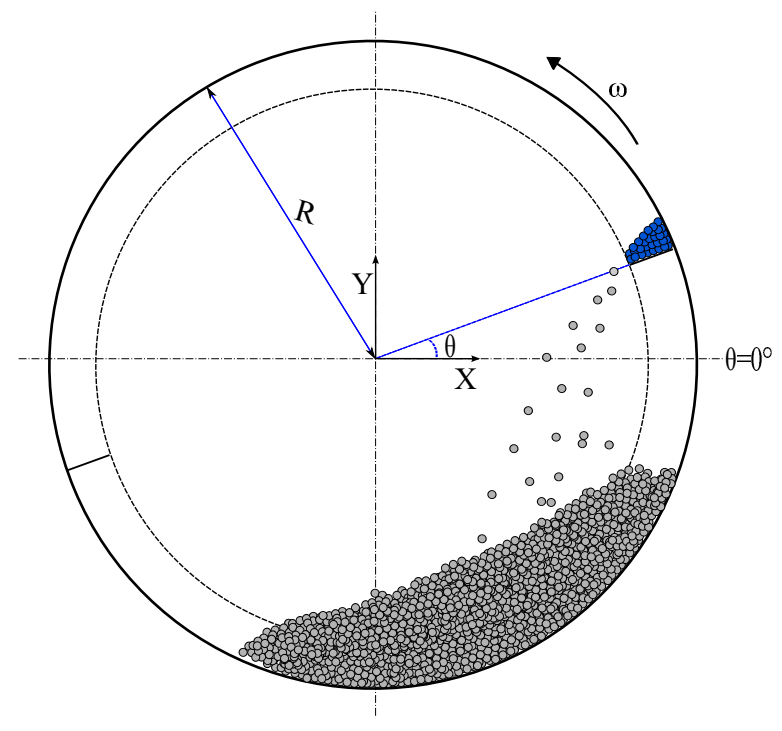

Figure 1. Drum's section used during the simulations

of the granular motion along the tube [7], we have used a portion of the rotating drum with thickness of $0.01 \mathrm{~m}$. The diameter is also reduced in order to minimize the particles number. The diameter, $D$, is equal to $0.16 \mathrm{~m}$ (Fig. $1)$. This portion is driven with rotation speed $\omega=16 \mathrm{rpm}$. The Froude number is equal to 0.02 . It corresponds to the cascade regime for a filling degree $\tau>0.1$ according to [14]. Where $\tau$ express the volumetric filling percentage of drum's load $\left(\tau=\frac{V_{\text {Material }}}{V_{\text {Drum }}}\right)$.

In industry, the number of the flights is calculated to insure a maximum holdup. In the present study, in order to avoid interaction between the flights, we have used only two opposite flights. Thus the portion of the tube is fitted with flights composed of two segments which have the same length $l$ of $0.0075 \mathrm{~m}$. Three profiles of flights are considered for which the angle $\alpha_{1}$ between the segments is $180^{\circ}, 120^{\circ}$ and $90^{\circ}$ (Fig.2). The angle $\alpha_{0}$ of fixation of the flights on the drum wall is $90^{\circ}$. Each flight is drawn in Fig. 2 at $\theta=0^{\circ}$, where the flight is supposed to be filled at it's maximum hold-up [7], [6]. In the approach of bulk material, the free surface is an inclined line with an angle equal to the dynamic angle of repose, $\Phi$, which is equal to the static angle of repose $\left(\Phi_{0}\right)$ at $\theta=0^{\circ}$. This dynamic angle depends on the rotation speed, drum's radius and friction coefficient as it was demonstrated by Schofield and Glikin [15] by studying the equilibrium of a particle about to fall from the flight. The volume of material in the flight can be calculated by the formula given in [5] for angled flight with two segments or in [9] for right angled flight. For three segments flight, a similar formula can be found in [8].

In our simulations, the particle-particle and particlewall collision are modelled through the soft-sphere approach. This was used to simulate particle-to-particle and particle-to-wall contact interaction. The model is used due to its accurate and efficient force calculation. It is based on Hertzian contact theory when calculating the normal force

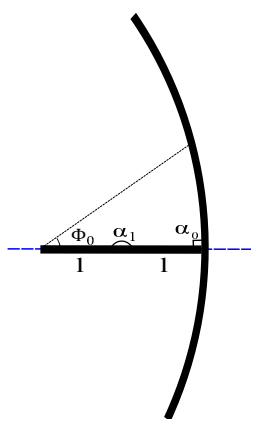

(a) Straight flight $\left(\alpha_{0}=90^{\circ}\right.$ $\left.\alpha_{1}=180^{\circ}\right)$

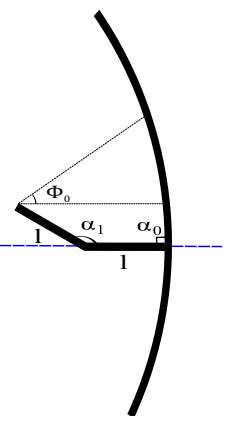

(b) Large angled flight $\left(\alpha_{0}=90^{\circ}\right.$, $\left.\alpha_{1}=120^{\circ}\right)$

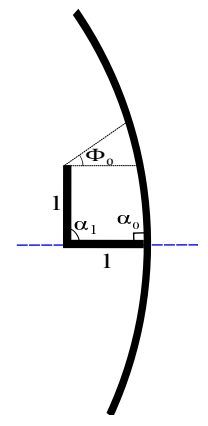

(c) Right angled flight $\left(\alpha_{0}=\alpha_{1}\right.$ $\left.=90^{\circ}\right)$
Figure 2. Three differents flight's shapes

Table 1. Physical parameters of the particle and of the tube used in the numerical simulations

\begin{tabular}{lll}
\hline & Particle & Tube \\
\hline Poisson's ratio & 0.3 & 0.3 \\
Shear modulus $(\mathrm{Pa})$ & $2.00 \mathrm{E}+07$ & $7.00 \mathrm{E}+07$ \\
Density $\left(\mathrm{kg} / \mathrm{m}^{3}\right)$ & 2600 & 7800 \\
Coefficient of restitution & 0.1 & 0.24 \\
Coefficient of static friction & $5.45 \mathrm{E}-01$ & $5.45 \mathrm{E}-01$ \\
coefficient of rolling friction & 0.01 & 0.01 \\
\hline
\end{tabular}

component and the work of Mindlin-Deresiewicz when determining the tangential force [16], [17].

Particles are considered spherical and the dryer is made of steel. Particles have a radius of $r=0,00075 \mathrm{~m}$ resulting in the use of 9558 particles to acheive $\tau=15 \%$ as a filling degree, with a porosity of 0.44 , corresponding to a random loose packing [18]. This value has been verified later on with an image analysis software on some images of our configuration obtained by EDEM. Characteristics of the materials used are shown in table 1.

\section{Results}

In order to increase the drying efficiency, it is recommended to increase the density of material in the airborne phase (particles flying through the cross-section of the drum) particularly in the upper half of the drum [5], [4]. Thus most of the studies consider the quantity of particles in the upper half of the drum as a design criterion [15], [7], [6]. We have applied this criterion and have calculated the variation of the particles number in this upper half of the drum.

In Fig. 3, we see the change of volume of material on the flight from $\theta=0^{\circ}$ up to complete discharge. To compare all flight's shapes we have drawn the relative volume of particles in the flight. This volume is calculated according to a constant porosity, equal to 0.44 .

In order to compare the behaviour of the flights, we have divided this volume by the capacity of each flight for $\theta=0^{\circ}$. In this figure, we have also drawn the holdup of right angled flight with the approach of bulk material developed by Sunkara and al. [9]. The angle $\alpha_{1}$ between 


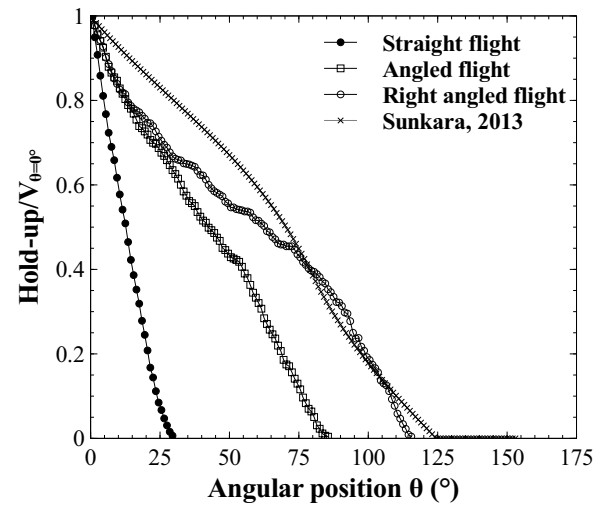

Figure 3. Relative hold-up in the flight, where $V_{\theta=0^{\circ}}$ is the holdup at $\theta=0^{\circ}$ : for a straight flight $V_{\theta=0^{\circ}}=111 \mathrm{~cm}^{3} / \mathrm{m}$, for an large angled flight $V_{\theta=0^{\circ}}=119 \mathrm{~cm}^{3} / \mathrm{m}$ and for a right angled flight $V_{\theta=0^{\circ}}=72.8 \mathrm{~cm}^{3} / \mathrm{m}$

the two segments influences the discharging profile of the flight. The time the flight takes to be completely empty is more important for an angle $\alpha_{1}=90^{\circ}$. This favours the presence of particles in the cross section of the tube for a long period. Even though straight flight carries more particles $\left(V_{\theta=0^{\circ}}=111 \mathrm{~cm}^{3} / \mathrm{m}\right)$. Its angular discharging angle, for which the flight is completely empty, is small.

In figure 4, we present the flight's cascading rate which varies from one flight to another. The number of particles leaving the flight is more or less constant over time for a right angled and a large angled flight.

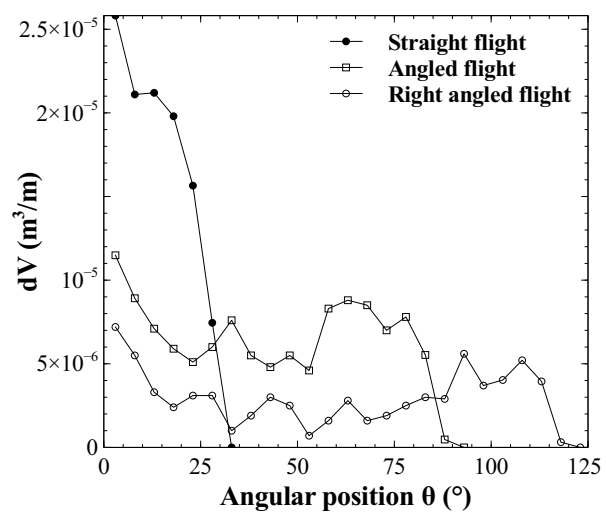

Figure 4. Flight cascading rate as a function of the angular position for different flight's shape

Snapshots of the behaviour of the granular material in the drum are presented in Fig. 5. These snapshots show that the flight profile affects the behaviour in the crosssection of the drum. The particles are concentrated in a small zone for the straight flight. However for the angled flight, a more extended zone is observed. Fig. 5 also illustrate both the hold-up in the flight and the particle curtain, which appear to have a constant width for angled flights and change shape for a straight flight. A straight flight has the maximum initial volume, but a Right-angled flight carries the particles higher. So for further characterization of the particles movement, we calculate the falling length and falling time. The falling length is the distance traveled by the particle from the flight's tip up to the contact point with the bed of material or the drum's wall. And the falling time is the time the particle takes to travel the falling length.

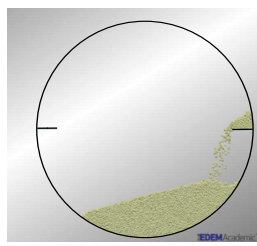

(a) $\theta=0^{\circ}$

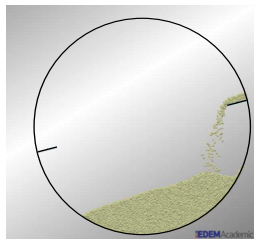

(d) $\theta=14^{\circ}$

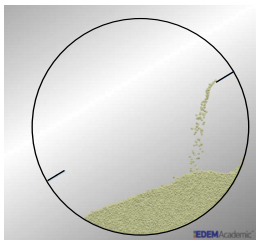

(g) $\theta=29^{\circ}$

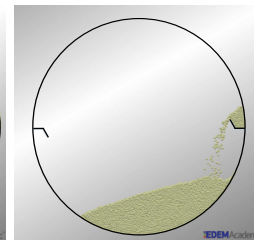

(b) $\theta=0^{\circ}$

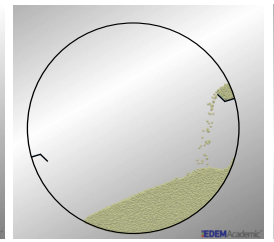

(e) $\theta=14^{\circ}$

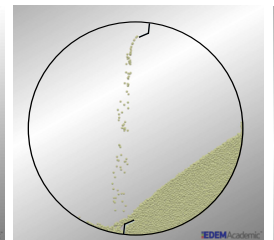

(h) $\theta=83^{\circ}$

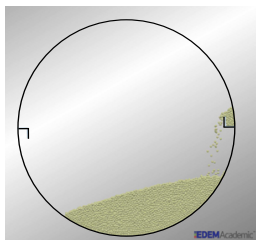

(c) $\theta=0^{\circ}$

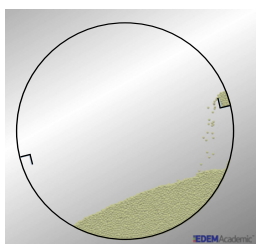

(f) $\theta=14^{\circ}$

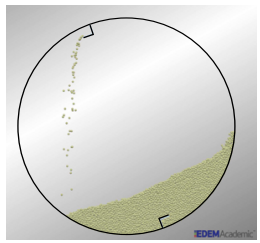

(i) $\theta=115^{\circ}$
Figure 5. Snapshots of the granular behaviour in the rotating drum for three shapes of the flight

The dispersion of the falling length and the falling time is not the same from one flight shape to another, leading to different discharging patterns. Since the number of particles leaving the flight is important and depends on the angular position of the flight, we calculate the average falling length and falling time over an angular range of $1^{\circ}$ to present the results and to ease the comparison between the flight's shapes (Fig. 6,7). The more we reduce the angle $\alpha_{1}$ between the segments of the flight, the greater the range of the discharging flight. Moreover, when calculating the average falling length and falling time of all particles leaving each the flight, the results show an increase in the falling length and the falling time up to $50 \%$ and $70 \%$, respectively, when using a right-angled flight instead of a straight one.

\section{Conclusion}

The shape of the flight influences the discharging pattern of the granular material retained in the flight. Compared to the other flights an angled flight with $120^{\circ}$ offers a large angular discharging range while carrying an important quantity of material compared to a right-angled flight. The falling length and the falling time of the particles also increases up to a maximum value then they start decreasing for a large-angled flight and a Right-angled flight. 


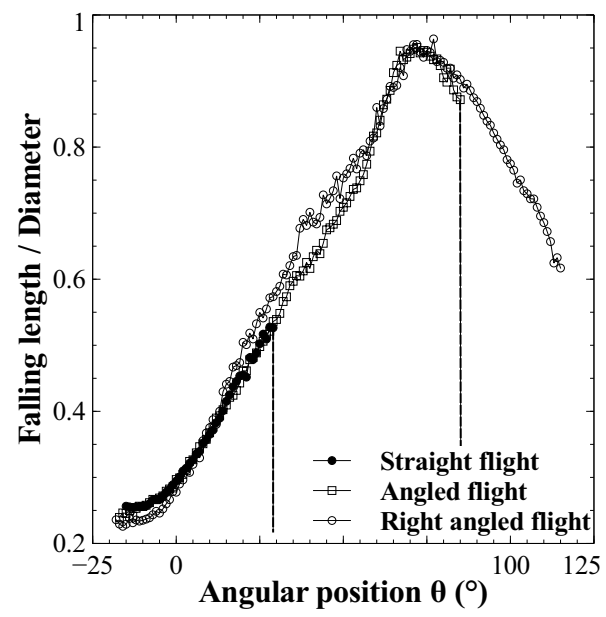

Figure 6. Falling length of the particles, for three different flight profiles. Vertical lines show the angular discharging angle

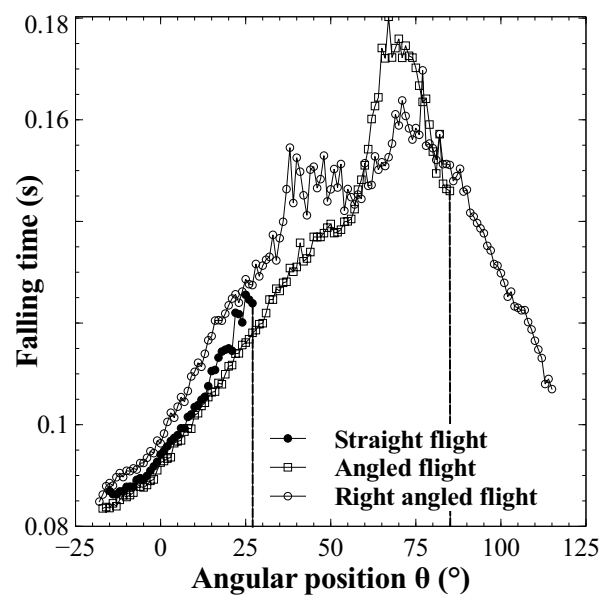

Figure 7. Falling time of the particles, for three different flight profiles. Vertical lines show the angular discharging angle

Compared to the other flight's shape, the angled flight offers a compromise between the angular discharging range and the falling length and falling time. It allows to get greatest falling length and time without decreasing afterwards as with a right-angled flight. The angular discharging rate is optimum compared to a straight flight.

Although the comparaison between the hold-up given by Sunkara's equations [9] and DEM's simulations shows the same tendancy. However, DEM's simulations offer a more accurate calculations of the flight's hold-up since the DEM takes into account the interactions between particles and the particle's size unlike the bulk material's approach.

\section{Notations}

$\mathrm{D}$ : dryer diameter $(\mathrm{m})$

$\mathrm{L}:$ length of the dryer $(\mathrm{m})$ $\mathrm{r}$ : particle radius $(\mathrm{m})$

1 : length of the flight segment $(\mathrm{m})$

$\omega:$ dryer rotational seed $(\mathrm{rad} / \mathrm{s})$

$\tau:$ drum's filling degree $(\%)$

$\theta:$ angular position of the tip of the flight $\left(^{\circ}\right)$

$\alpha_{0}$ : angle between the fist segment and the wall $\left(^{\circ}\right)$.

$\alpha_{1}$ : angle between the segments of the flight $\left(^{\circ}\right)$

$\Phi$ : the dynamic angle of repose $\left(^{\circ}\right)$

$\Phi_{0}$ : the static angle of repose $\left(^{\circ}\right)$.

\section{References}

[1] R. B. Keey, Drying : Principles and practice (Pergamon Press, 1972)

[2] H. Henein and JK. Brimacombe and AP. Watkinson, Metallurgical transactions B 14, 191-205 (1983)

[3] A. S. Mujumdar, Handbook of industrial drying (Crc Press, 2014)

[4] R. G. Sherritt, and R. Caple, The Canadian Journal of Chemical Engineering 71, 337-346 (1993)

[5] M. H. Lisboa and D. S. Vitorino and W. B. Delaiba and J. R. D. Finzer, and M. A. S. Barrozo. Brazilian Journal of Chemical Engineering, 24, 365-374 (2007)

[6] C.G.J. Baker, Drying Technology 6, 631-653 (1988)

[7] P. G. Glikin, Chemical Engineering Research and Design 56a, 120-126 (1978)

[8] D. Revol and C.L. Briens and J.M. Chabagno, Chemical Powder Technology 121, 230-238 (2001)

[9] K. R. Sunkara and F. Herz, and E. Specht and J. Mellmann and R. Erpelding. Powder technology, 234, 107116 (2013)

[10] M, Riccardo and De R. S. Kiesgen and M. Guillain and W. Gabriel. Powder technology, 286, 732-739 (2015)

[11] P. Van Liedekerke and E. Tijskens and E. Dintwa and F. Rioual and J. Vangeyte and H. Ramon. Powder technology, 190, 348-360 (2009)

[12] S.J. Friedman and W.R. Marshall, Chemical engineering progress 6, 482-493 (1949)

[13] N. A. S. Bongo and S. Vitu and M. Clausse and J-L. Dirion and M. Debacq, Powder Technology 269, 554565 (2015)

[14] J. Mellmann, Powder Technology 6, 251-270 (2001)

[15] F. R. Schofield and P. G. Glikin, Trans I Chem E 40, (1962)

[16] R. D. Mindlin, Journal of Applied Mechanics 16, 259-268 (1949)

[17] R.D. Mindlin and H. Deresiewicz, Journal of Applied Mechanics 20, 327-344 (1953)

[18] F. Lominé, Ecoulement de Particules dans un Milieu Poreux (PHD dissertation, Université de Rennes I, France, 2007) 